\title{
A Medical Disposable Supply Demand Forecasting By Moving Average And Exponential Smoothing Method
}

\author{
H D E Sinaga ${ }^{1}$, N Irawati² \\ Computer Science/Informatics Study Program, STMIK Royal Kisaran, Asahan, Indonesia ${ }^{1}$, \\ Prof.HM. Yamin 173 Kisaran, Sumatera Utara, Indonesia, $21222^{2}$. \\ \{omisinaga@yahoo.com ${ }^{1}$,novicairawati11@gmail.com²\}
}

\begin{abstract}
Medical disposable is one of the important support tools in medical operational and must not be out of stock in order to deliver excellent service in hospital. The pharmacy department has to forecast the demand to supply information for decision making in budgeting. Since the pharmacy still has no forecasting method then in this paper compare single moving average and single exponential smoothing technique.The accuracy of forecasting is the most important and it can be measured with RMSE (Root Mean Square Value). The smallest value of RMSE is having high accuracy of forecasting. The method that has smallest RMSE (66.19) is Exponential Smoothing method with $\alpha=0.1$ and be the best option to use a method to forecast the medical disposable supply demand.
\end{abstract}

Keywords: Medical Supplies Demand, Forecasting, Moving Average, Exponential Smoothing.

\section{Introduction}

Hospitals as the healthcare center for civils, in fact must need health care facilities in order to facilitate its operational.

Health care facilities are the instruments, apparatus, machines, and implants that are not containing medicines that are used to prevent, diagnose, cure and alleviate illness, take care patients and recover human health, and form structures and repair the body's function.

Health care facilities have a very important role in medical service especially in Hospitals as health care support or examining process for the patient. Medical disposable is a single used tool that has to be disposed of after one-time usage or cannot be re-used.

Therefore, in order to deliver excellent service to civilians without any hindrance, hospitals normally have enough supply to comply the availability of the medical disposable supply. In case of medical disposable supply are out of stock, it may impact on the level of distrust of the civilians towards the health care institutions.

Legally, Permenkes RI No.35 year 2014 chapter 6 has stated that the pharmacy is obliged to make sure the availability of medical disposable stock[1].

The pharmacy department in HAMS hospital is the one responsible for supplying medical disposable to the patients. This department is responsible to ensure and control the availability of medical disposable supply to avoid from out of stock to serve the patients. 
The Pharmacy division recently has no certain plan to forecast the demand for medical disposable. The current estimations for the supply of the medical disposable are based on the previous actual demand. It is then causing the organizing process at pharmacy department does not work efficiently and effectively. The absence of good planning on demand for medical disposable may also impact the decision making of budgeting process. As in common hospitals, budgetary pressure is usually set tight so the budget planning of disposable supply has to be predicted fine.

Therefore, in this paper, we focus on an analysis of comparison time series forecasting the demand using Moving Average and exponential smoothing techniques to get the best result of the forecast demand that can be used for the pharmacy.

\section{Related Works}

There are many different kinds of medical disposable and health care tools which often to be used in the hospital. Health care tools are including instruments, apparatus, machines, and implants which do not contain medicine. These are used to prevent, diagnose, recover illness and take care of patients as well as recover human health and fix the function of the human body.

Some examples of medical disposable are syringe (spuit), muslin, infusion bag, infusion pipe, oxygen pipe, bandage, urine bag, mask, medical hand gloves (handscoon), - etc.

This disposable supply has important role in medical environment especially in hospitals as the tools for care support or for the patient's examination.

Medical disposable means for single use only. Single-use in this case means it has to be thrown away after one-time usage and cannot be re-used to the same patient or even to different patients [2].

It has to be dismissed after one-time usage. The purpose of dismissing these tools is to prevent transmission of any kind of virus or bacteria from one human to another. Therefore, the safety standard of the hospital for its medical personnel can be maintained.

The current use of single-use disposables in healthcare, however, has become costly and wasteful.

In fact, hospitals are obliged to maintain the supply of medical disposable are more than enough, since a patient may use more than one medical disposable.

In hospital HAMS, there is about 185 kind of medical disposable that needs to be forecasted their demand[3].

\subsection{Time series forecasting}

A time series is a sequence of measurements over time, usually obtained at equally spaced intervals.

Forecasting is a technic to analyze calculation which is using a qualitative method or quantitative to estimate future conditions by using previous data for reference.

Based on Heizer and Render[4], forecasting is an art and science to predict future events. Forecasting may involve taking historical data (such as past sales) and projecting them into the future with a mathematical model.

Time series forecasting involves taking models to fit on historical data and using them to predict the future trend. 
This technique is widely used in many areas which require forecast as estimation of economic development, forecasting of water demand for water supply companies, forecasting the crude oil prices, forecasting, forecasting electricity generation capacity, etc[5]-[7].

From various definitions above, therefore we can come up with the conclusion that forecasting the medical disposable is the future demand whereas in the calculation of the forecast may need previous data of medical disposable usage. Therefore the accuracy of the medical disposable forecast will highly affect the accuracy of budget planning.

\subsection{Moving Average and Exponential Smoothing Method}

The moving average forecast uses a number of historical actual data values to generate a forecast. It is useful for a fairly steady demand over time[4]. It is weighting the past observation equally and is the unweighted mean of the previous amount data.

$$
\widehat{Y}_{t+1}=\frac{Y_{t}+Y_{t-1}+\cdots+Y_{t-n+1}}{m}
$$

Where $\widehat{Y}_{t+1}$ is the forecast at the period $(\mathrm{t}+1), Y_{t}$ is actual value at period $\mathrm{t}$, and " $\mathrm{m}$ " is the previous day's values? This method is simple to calculate but not suitable for data that have the trend[8].

To measure the difference between values predicted and actually observed values then we use Root Mean Square Values (RMSE).

$$
\mathrm{RMSE}=\sqrt{\frac{\sum\left(Y_{t}-Y_{t+1}\right)^{2}}{n}}
$$

Where $\mathrm{n}$ is observed data.

Exponential smoothing methods are the most widely used forecasting methods. The formulation of exponential smoothing forecasting methods arose in the 1950s from the original work of Brown[1] and Holt[9] who were working on creating forecasting models for inventory control systems. The simple exponential smoothing is a technique for smoothing time series data using the exponential function to assign exponentially decreasing weight over time. It is suitable for forecasting data with no trend or seasonal pattern. This method calculated using weighted averages where the weight decrease exponentially as observations come from further in the past. The smallest weight is associated with the oldest observations. The smoothing parameter $\alpha$ is between 0 and 1 . The closer $\alpha$ to 0 then the more weight is given to observations from the more distant past. The more close $\alpha$ to 1 then the more weight is given to recent observations[3].

$$
\widehat{Y}_{t+1}=\alpha Y_{t}+(1-\alpha) \widehat{Y}_{(t+1)-1}
$$

In this paper, both methods are applied to forecast the medical disposable supply-demand at Public Hospital HAMS, Kisaran, Sumatera Utara, Indonesia. The mathematical model (1) and (3) are observed by taking sample of the $3 \mathrm{ml}$ spuit (as the medical disposable supply) demand for 180 days.

The simple moving average method is using a 3-point moving average. The single exponential smoothing is using $\alpha=0.1,0.3$. 


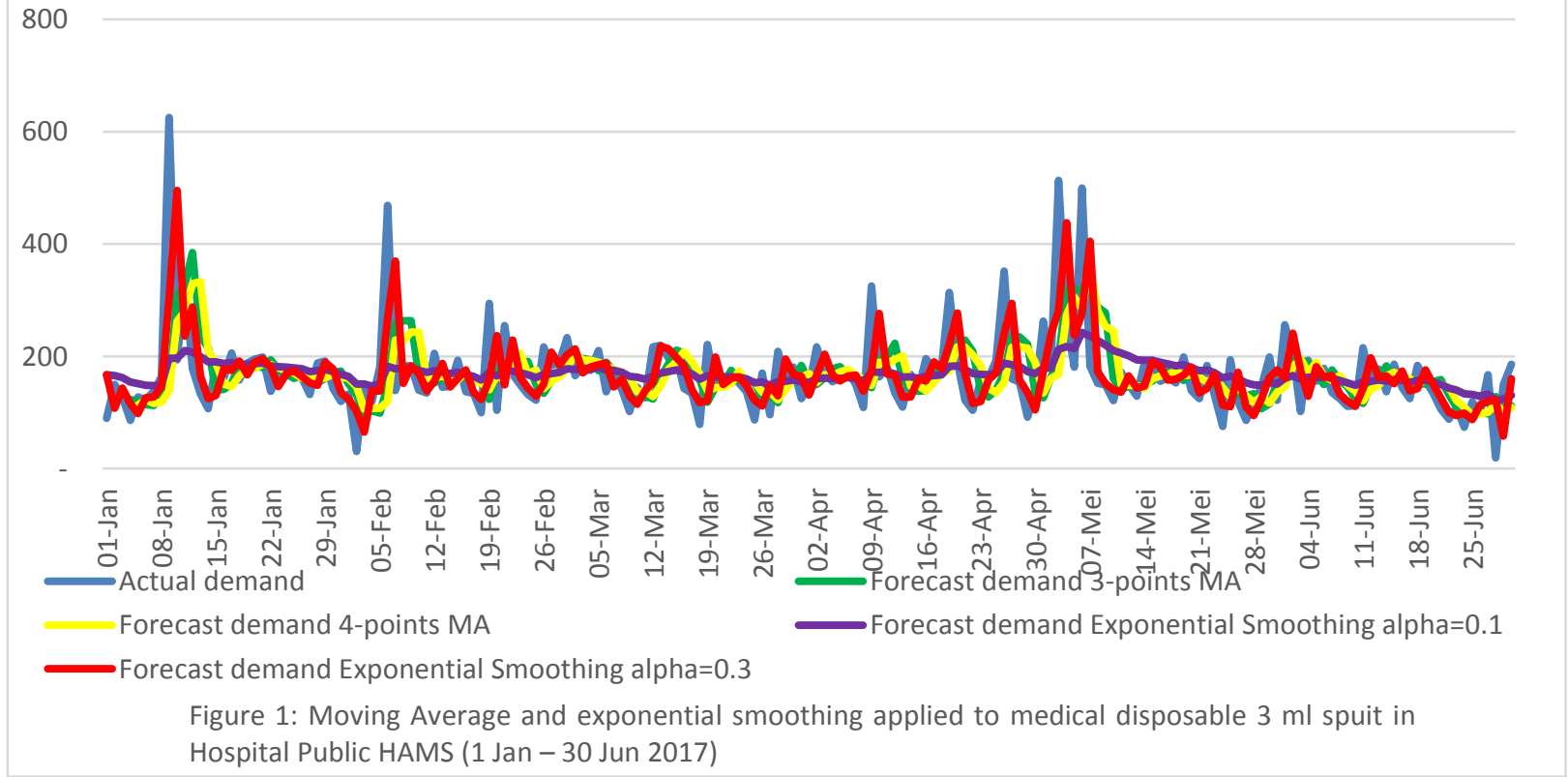

Accuracy is typically assessed using RMSE. By comparing RMSE for the two methods then the best method chosen is which has the smallest RMSE.

\section{Result}

The calculation of RMSE (2) are showed in the table below:

Table 1: Comparison RMSE between 4 models

\begin{tabular}{ll}
\hline Method & RMSE \\
\hline Moving Average 3 points & 79.07 \\
\hline Moving Average 4 points & 81.16 \\
\hline Exponential Smoothing $\alpha=0.1$ & 66.19 \\
\hline Exponential Smoothing $\alpha=0.3$ & 68.23 \\
\hline
\end{tabular}

As shown in Fig.1, the purple line, ie.forecast demand with the exponential method $\alpha=0.1$ shows the smooth fluctuations in forecast demand

\section{Conclusion}

The moving average and exponential smoothing have similar defects of introducing a lag relative to the input data.

The exponential smoothing method still has a smaller value of RMSE compare to moving average method.

The calculation of RMSE shows that the exponential smoothing method with $\alpha=0.1$ has the smallest value. And an observation using $\alpha=0.3$ does not detect any significant differences 
between using $\alpha=0.1$. It means that the exponential smoothing method with $\alpha=0.1$ has the highest accuracy among the other methods and can be recommended to be used as an application to forecasting the medical disposable supply-demand in the public hospital HAMS.

\section{References}

[1] R. G. Brown and R. F. Meyer, "The Fundamental Theorem of Exponential Smoothing," Oper. Res., vol. 9, no. 5, pp. 673-685, 1961.

[2] N. B. Engineers, Handbook on Medical and Surgical Disposable Products. Delhi: Niir Project Consultancy Services, 2014.

[3] W. Enders, Applied Econometric Times Series. United States: Wiley, 2014.

[4] J. Heizer, B. Render, and C. Munson, Operations Management. Sustainability and Supply Chain Management. Boston: Pearson, 2014.

[5] I. Majerová and T. Pražák, "Estimation of Economic Development in Papua New Guinea: Linear Trend Analysis or Moving Average Model?," Procedia - Soc. Behav. Sci., vol. 110, pp. 450-460, Jan. 2014.

[6] E. Kozłowski, B. Kowalska, D. Kowalski, and D. Mazurkiewicz, "Water Demand Forecasting by Trend and Harmonic Analysis," Arch. Civ. Mech. Eng., vol. 18, no. 1, pp. 140-148, Jan. 2018.

[7] S.-P. Jun, T.-E. Sung, and H.-W. Park, "Forecasting by Analogy Using The Web Search Traffic," Technol. Forecast. Soc. Change, vol. 115, pp. 37-51, Feb. 2017.

[8] Pittayachaichoopara, "Inventory Management Using Demand Forecasting Model For Medical supplies in Surgery Department," in Proceedings of 23rd, The ITER International COnference, 2015, no. April, pp. 23-26.

[9] C. C. Holt, "Forecasting seasonals and trends by exponentially weighted moving averages," Int. J. Forecast., vol. 20, no. 1, pp. 5-10, Jan. 2004. 